\title{
Automatic Estimation System of Building Frames Integrated with Structural Design Information (AutoES)
}

\author{
Chaeyeon LIM ${ }^{1}$, Donghoon $\mathrm{LEE}^{2}$, Won-Kee HONG ${ }^{3}$ and Sunkuk $\mathrm{KIM}^{3} *$ \\ ${ }^{1}$ PhD candidate, Department of Architectural Engineering, Kyung Hee University, Republic \\ of Korea \\ ${ }^{2}$ PhD, Department of Architectural Engineering, Kyung Hee University, Republic of Korea \\ ${ }^{3}$ Professor, Department of Architectural Engineering, Kyung Hee University, Republic of \\ Korea
}

*Corresponding author's e-mail: kimskuk@khu.ac.kr

\begin{abstract}
The project participants, including clients, architects, structural engineers and contractors would want to know accurate construction costs as soon as the design is completed. However, it may take at least several weeks for the cost estimation after the structural design and drawings are completed, depending on the project scale or size. Quantity surveying in manual is time-consuming and taken by lots of effort. Even if computerized software is used, it takes a lot of time to insert structural design information to the software. In addition, the estimated cost may result in inaccurate quantity owing to the drawing errors or quantity surveyors' mistake, as well as it is not an exact quantity for actual construction, exposing numerous problems at the construction phase. For instance, to accurately estimate the quantity of rebar, some additional effort is required such as preparing the bar bending schedule. Such problems occur by the communication gap and viewpoint difference among project participants who perform structural designs, draft the structural drawings and estimate quantity. But, if structural design information can be automatically received for quantity estimation, an exact quantity can be estimated without omission or errors. To solve those problems, this study proposes automatic estimation System of building frames integrated with structural design information (AutoES). Using the algorithms provided by AutoES, the task of cost estimation can be accomplished with an exact bill of quantity including a bar bending schedule without errors, mistakes, or omission within a week, which used to take at least 4 weeks.
\end{abstract}

\section{KEYWORDS}

automatic estimation; building frame; structural design; information; algorithm; integrated project delivery

\section{INTRODUCTION}

Project participants like clients, architects or structural engineers and contractors would like to know the accurate construction cost as soon as the design is completed. However, it takes at least a few weeks for the construction cost to be estimated including the structural design and drawings although it may vary according to the size of structural design. Currently in Korea, when the structural analysis and drawings of a building are completed from a structural engineer, the structural engineer or subcontractor prepares the structural drawings. Then, the 
structural engineering office or another specialized company calculates the estimated quantity, prepares bill of quantity based on the estimated quantity and estimates the design cost. Here, unlike the actual quantity, the estimated quantity refers to the quantity roughly estimated, including the places and location of the rebar banding margin. Additionally, the contractor calculates the quantity for the given contract and prepares the bill of quantity for bidding. After the contract is concluded, the quantity for construction is recalculated at the construction phase for purchasing and procurement of materials, and the construction (Kunwon engineering, 2009; Halpin and Senior, 2011). There are mainly 2 reasons in estimating the quantity several times with excessive input of manpower for a single project.

First, this is because the person in charge of calculating the quantity at each phase varies (Ssangyong Engineering \& Construction Co. Ltd., 1998) and the standard of quantity estimation may change according to the purpose of such estimation performed by each person (Lee et al., 2008). In particular, the quantity and unit price may alter depending on the construction method applied to the same structure. Furthermore, the quantity estimated by each person may not be accurate owing to mistakes like omission or miswriting. To reduce such excessive manpower, lately manual work is discouraged and a computer-based software is used instead (Lee et al. , 2009).

Second, this is due to the fact that the information used for quantity estimation such as the drawings and specifications is not 100\% reliable (Monteiro and Martins, 2013). The person responsible for estimation at each phase should identify the architect's or structural engineer's intention using documents like drawings and specifications. However, such documents are also prepared manually, so inaccurate quantity may be estimated caused by errors like omission or miswriting during format exchanging or import-export process, even if the estimator does not make any mistake (Monteiro and Martins, 2013). That is, all participants including the people who prepare the structural calculation sheet, structural drawings and field guides as well as the estimators should not make mistake for estimation of accurate quantity and price. Yet, those who prepare such design drawings and specifications vary and since it relies on manpower, human errors may occur (Monteiro and Martins, 2013). The quantity estimated through the process described above may differ from the exact quantity for actual construction, so the contractor recalculates the actual quantity for construction after the contract is concluded (Kunwon engineering, 2009). For instance, in case of reinforcement bars, a shop drawing is prepared in the construction phase and then a bar bending schedule is completed. So, additional time and effort is needed for estimation of accurate quantity (Lee et al., 2009).

One thing in common about those two reasons is that human errors may be generated during the work performed by people. If there is software composed of accurate algorithms, such errors may not be generated. Especially, the structural calculation sheet and structural drawings and specifications are driven from a structural analysis model, which are the most important information for quantity estimation. In other words, if quantity can be estimated by extracting the original data from a structural analysis model using the software, most errors can be prevented and the actual quantity can be quickly and accurately estimated with less manpower.

In this regard, this study proposes Automatic Estimation system of building frames integrated with structural design information (AutoES). AutoES is based on the structural analysis model, so the scope is limited to the quantity of structural works. The procedure of this study is as follows: 1) Preliminary study is conducted to examine the literature and commercial software related to quantity estimation. 2) The concept of AutoES and main process is proposed. 3) The detailed algorithms of AutoES are presented and they are explained with a case respectively. It is expected that when such algorithms are incorporated to software, the 
information used in the software, the information created in the process of calculation and the result can be used for development of automatic drafting algorithms of structural drawings.

\section{PRELIMINARY STUDY}

\section{Manual quantity estimation}

Project participants like clients, architects or structural engineers and contractors would like to know the accurate construction cost as soon as the design is completed. However, it takes at least a few weeks for the construction cost to be estimated although it may vary according to the size of structural design (Kunwon engineering, 2009; Halpin and Senior, 2011). Generally, the construction industry performs structural analyses and designs after an architectural design is completed. When the structural analyses and designs are completed, a structural calculation sheet and structural drawings are prepared (Halpin and Senior, 2011). Afterwards, the person in charge of quantity estimation estimates the quantity based on the architectural and structural drawings and specifications, in order to calculate an expected price and a bidding price (Kunwon engineering, 2009). As the contract is concluded, the contractor implements the construction.

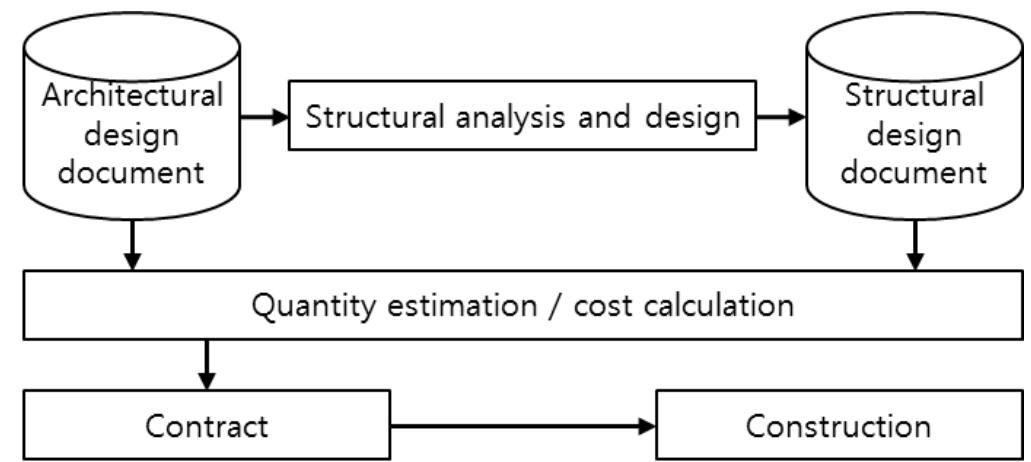

Figure 1. Simplification of the process from the structural design to the construction

\section{Application of quantity estimation software}

The software for quantity estimation can be largely classified into estimation software and BIM. The study investigated the accuracy of quantity estimation on 7 estimation software used globally. Among these software, 3 software were found to estimate quantity based on extra coefficient on an opening or lapping and embedment length of rebar. The result of quantity estimation based on such extra length resulted in more concrete than the actual input quantity and less rebar and forms than the actual input quantity (Kim and Park, 2006). Unlike the previously mentioned 3 software, the remaining 4 types of software were found to relatively estimate the details with accuracy quantity. These software estimates the quantity by recognizing the drawings or when users insert data based on the architectural and structural drawings. The main function of software is to provide calculated results based on the inserted data and it is time-consuming to insert such data (Lee, 2014).

\section{BIM-based quantity estimation}

Mainly used BIM software includes ArchiCAD, Revit, Microstation, Allplan, ParaCloud Modeler and Tekla Structure (Kim et al., 2014). Efforts regarding the development and improvement of BIM-based cost estimation include: a conceptual approach to cost estimation of structural skeleton using an interactive automation algorithm (Jadid and Idress, 2007); and a 
comparative study of commercially available BIM-based cost estimation software and an investigation of the changes in work practices and workflows incurred by the adoption of such software by a construction company (Forgues et al., 2012). Some case studies reporting on the results of BIM-based cost estimation are also available (Eastman, 2008; McGraw-Hill Construction, 2008; Yu et al., 2011). Likewise, most BIM tools are able to perform quantity surveying but these applications tend to lack the function to perform cost estimation, which is usually done using different software. The interaction between the BIM and the cost estimation applications is often ensured via IFC (Monteiro and Martins, 2013). The IFC has been the exchange format mostly used for BIM applications in recent years, however it does not perform flawlessly, as there is loss of information with each import-export process, which can lead to erroneous results, and ultimately, incorrect quantities and estimations (Zhiliang et al., 2011). For a fundamental solution of the problem, loss of information should be minimized by skipping format exchanges or import-export process of data. In other words, it is necessary to have detailed quantity estimation algorithms within the structural analysis and design software so as to use the original structural design information, which is the master data for quantity estimation.

\section{AUTOMATIC ESTIMATION SYSTEM}

\section{Algorithm concept}

According to Section 2, the necessity of automatic quantity estimation algorithms using the structural design information is drawn. In this regard, this study proposes AutoES. AutoES is software that converts the existing procedure of quantity estimation on the left into the one on the right as illustrated in Figure 2. Figure 2 shows the difference between the existing process and the AutoES process. AutoES estimates the quantity using the structural analysis model and structural design result, to avoid human errors and data loss. As examined in Section 2, the existing quantity estimation not only results in inaccurate results owing to human errors that may be generated in the process of preparing structural drawings and structural design reports and the process of data input, but also it is time-consuming. However, the structural drawings and structural design reports are driven from the structural design result. As shown in Figure 2, quantity estimation is possible by directly using the structural design result instead of going through the structural drawings and structural design reports. As demonstrated in Figure 3, AutoES involves 4 processes. All process includes an automatic algorithm and the details of each process are as described below.

\section{Member information classification}

As previously stated, AutoES uses the structural analysis model and structural design result for quantity estimation without data exchanges. Especially, when estimating the quantity of rebar, it is essential to use the structural analysis model for it needs to consider not just a single member, but connected members. Member information classification is conducted in 3 steps: Member classification, defining member connection and loading the member design data.

For example, when it is assumed that a structural analysis model exists as shown in Figure 4, a person will recognize element 3 as a column as soon as he/she sees the model. A structural analysis program will define element 3 as a column, but if the person who created the model made a mistake, it may be assigned as a different attribute instead of a column. In such a case, the coordinates of node 3 and node 8 that composes element 3 are searched using the algorithms, and if the $\mathrm{x}$-coordinate and the $\mathrm{y}$-coordinate are same and the $\mathrm{z}$-coordinate is 
different, it can be classified into a column. Likewise, in case of element 8 , the coordinates of node 7 and node 8 can be compared for classification into a girder.

Defining member connection refers to searching and defining the members connected based on the node. When the member design data from the structural design result is loaded to a member list that includes the member connection information created in the process above, the member information classification process is completed.

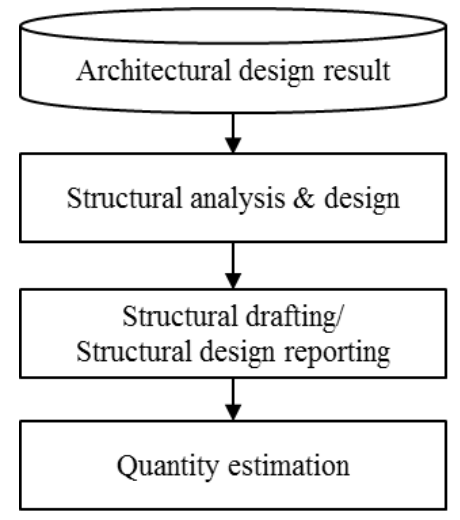

(a) Existing process

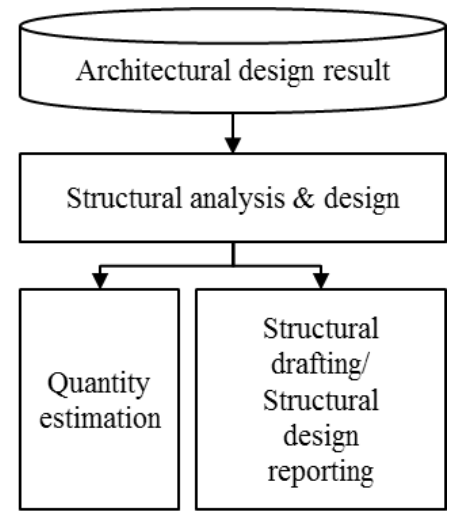

(b) AutoES process

Figure 2. Comparison of quantity estimation process

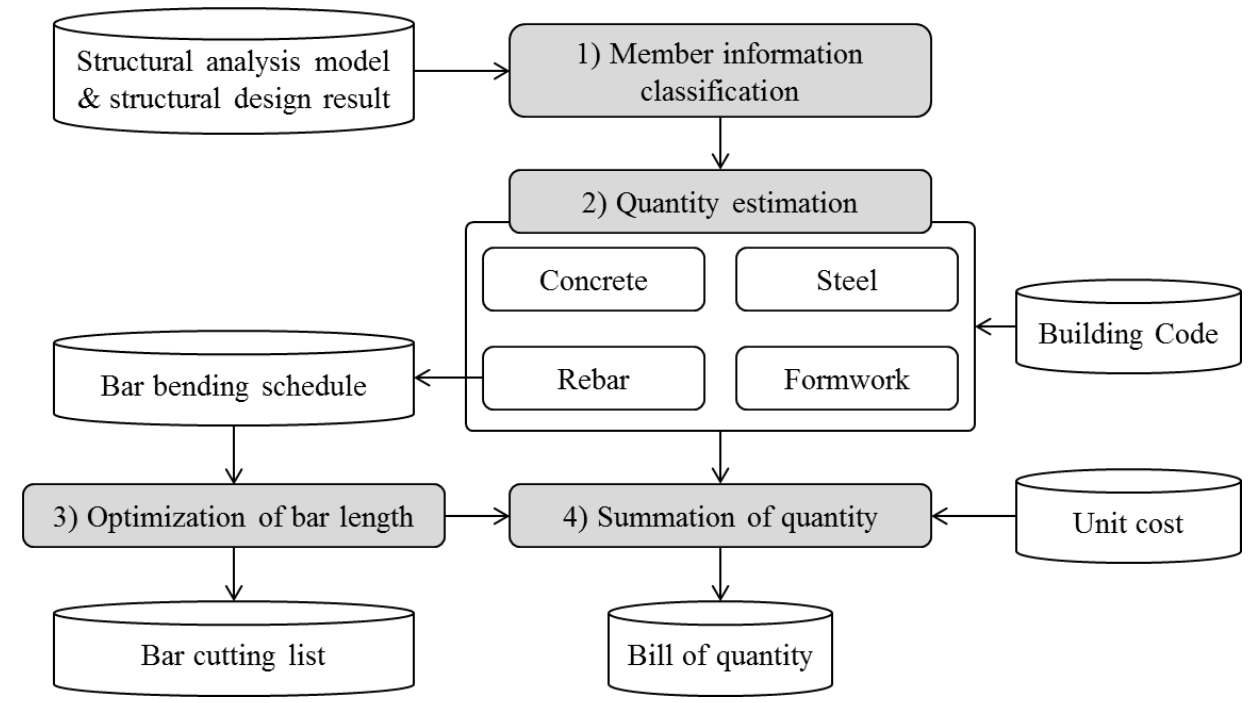

Figure 3. Process algorithm of AutoES

\section{Quantity estimation}

When a member list that includes the member connection information and design data is completed through member information classification process, quantity is estimated based on the list. Quantity estimation of 4 main resources, including concrete, formwork, steel and rebar that are required for structural works is conducted. The quantity of concrete is estimated based on the volume of members. Here, a boundary condition is defined based on the member connection information and the quantity is estimated through exclusion depending on the shape. For instance, the quantity of columns is estimated in consideration of the floor height, the quantity of girders in consideration of the net length that excludes the section of columns and the quantity of slabs in consideration of the width that excludes the width of column, 
girder and beam. The quantity of formwork is estimated using the boundary condition defined upon estimation of the concrete quantity, and measuring the surface area of member. The length of steel is estimated by cross-section. Unlike other resources, estimation of rebar quantity is complicated and errors are frequently found (Lee et al., 2009; Kim et al., 2010). Thus, the estimation of rebar quantity using AutoES is performed based on the predefined rebar classification to prevent omission or duplicated calculation. In addition, unlike the commercial software widely used, the detailed equation specified in the code is used for calculation of the lapping and embedment length to estimate the actual quantity.

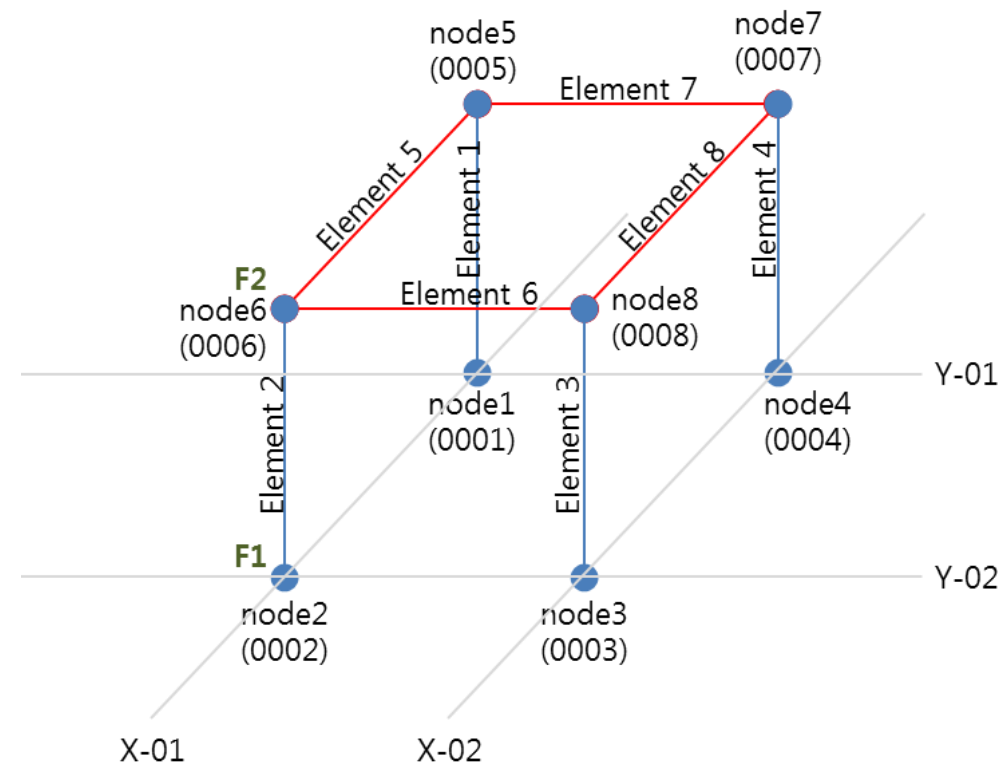

Figure 4. Example of structural analysis model

\section{Optimization of bar length}

As previously mentioned, estimating the quantity of rebar is complicated than that of other resources (Lee et al., 2008). AutoES estimates the quantity of rebar taking into account of not only the detailed equation for measurement of the lapping and embedment length and the banding margin presented in code, but also the boundary condition that includes the connection detail of member. A bar banding schedule can be immediately prepared using the information created in such process. It is impracticable to apply the rebar quantity estimated in the process above onto specifications. This is because of the machining accuracy of rebar and the loss that may be generated in the process of fabrication.

For instance, if it is estimated that $7.855 \mathrm{~m}$ of rebar is needed, it is difficult to precisely have $7.855 \mathrm{~m}$ of rebar, so it should be processed as $7.86 \mathrm{~m}$. However, to have $7.86 \mathrm{~m}$ of rebar, 0.14 should be cut off from the $8 \mathrm{~m}$-rebar and $1.14 \mathrm{~m}$ from the $9 \mathrm{~m}$-rebar and the rebar that is cut off is too short to be used in other places, treated as a loss. The concept of optimization in AutoES refers to the procedure of minimizing the loss of rebar.

Such optimization process calibrates the length of rebar based on the predefined or userdefined standard, and combines the rebar for minimization of loss. Let's assume that 20 reinforcement bars that are $11.285 \mathrm{~m}$ long, 30 that are $7.855 \mathrm{~m}$ long, 50 that are $4.5 \mathrm{~m}$ long and 30 that are $3.005 \mathrm{~m}$ long are needed. First, the lengths are revised into $11.29 \mathrm{~m} 7.86 \mathrm{~m}, 4.5 \mathrm{~m}$ and $3.01 \mathrm{~m}$. Then, number of cases is calculated to find the rebar combination with the least loss. In case of the rebar combination above, the $12 \mathrm{~m}$-rebar is used for the one that is $11.29 \mathrm{~m}$ long, the 9m-rebar for the one that is $4.5 \mathrm{~m}$ long, and the $11 \mathrm{~m}$-rebar is used for the 
combination of the rebar that is $7.86 \mathrm{~m}$ and $3.01 \mathrm{~m}$ long respectively. The overall loss will be around $2.3 \%$. However, minimization of loss through such rebar combination has a lot of constraints. For example, combination of the rebar needed in the $1^{\text {st }}$ floor and that needed in the $13^{\text {th }}$ floor may minimize the loss, but there may be a greater loss caused by missing reinforcement bars since there is a great time difference in using the rebar.

\section{Summation of quantity}

The quantities of concrete, formwork and steel estimated through the quantity estimation and the quantity of rebar revised through the optimization process are used for creating specifications. However, the quantity estimated is not applied to the specifications as it is. Many other items related to this other than the main resources estimated exist in the specifications. AutoES predefines the related items and changes the quantity or unit price of each detailed item depending on the construction method. For example, fabrication of rebar can be classified into on-site fabrication and on-plant fabrication. The AutoES user should choose either on-site or on-plant fabrication. Depending on the choice, the specification item, quantity and unit price will be changed. When the on-site fabrication is chosen, the labor cost for on-site fabrication will be allotted and when the on-plant fabrication is chosen, the unit price for on-plant fabrication and the quantity prior to the optimization process will be applied. This is because in case of a plant for rebar fabrication, optimization is done not only for a single site, but simultaneously in consideration of the rebar of other sites ordered to such plant for rebar fabrication.

\section{DISCUSSION AND CONCLUSION}

Project participants like clients, architects or structural engineers and contractors would like to know the accurate construction cost as soon as the design is completed. However, it takes at least a few weeks for the construction cost to be estimated although it may vary according to the size of structural design (Kunwon engineering, 2009; Halpin and Senior, 2011). In addition, the current quantity estimation is mostly the estimated quantity and the accuracy of such quantity cannot be ensured due to human errors (Monteiro and Martins, 2013). In this regard, this study proposed AutoES of building frames integrated with structural design information for reduction of manpower and time required for quantity estimation and improvement of quantity accuracy. The result of this study is following.

First, the studies related to commercial software for quantity estimation and rebar quantity estimation were examined to discover that inaccurate quantity is estimated in the construction industry owing to the human errors caused by manual estimation and the loss of information resulting from format exchanges or import-export process of data. It was drawn that it is necessary to develop automatic quantity estimation software that directly uses the structural design information.

Second, the concept of AutoES and process algorithms were proposed and each process was explained with a case (example). The algorithms presented in the study used the structural analysis model and structural design result for quantity estimation without data exchanges. This method can prevent human errors and loss of information that may be generated in the process of quantity estimation.

When AutoES proposed in the study is developed into software, it is expected that the actual quantity removed with various errors that may be generated in the process of quantity estimation can be quickly and accurately estimated. Furthermore, when a cad control algorithm is developed based on a wide range of boundary conditions defined in the process of quantity estimation, automatic design drawings may be fulfilled. 


\section{ACKNOWLEDGEMENTS}

This research was supported by the Ministry of Land, Infrastructure and Transport (MOLIT) of the Korea government and the Korea Agency for Infrastructure Technology Advancement (KAIA) (No. 13AUDP-B068892-01).

\section{REFERENCES}

Eastman C. (2008). "BIM Handbook a Guide to Building Information Modeling for Owners, Managers, Designers, Engineers and Contractors", John Wiley \& Sons, Ltd, New Jersey, 1-648.

Forgues, D., Iordanova, I., Valdivesio, F. and Staub-French, S. (2012) Rethinking the cost estimating process through 5D BIM: a case study., ASCE, Construction Research Congress, West Lafayette.

Halpin D.W. and Senior B.A. (2011). "Construction management 4th ed. International student version.” John Wiley \& Sons, Inc, Hoboken, 1-370.

Jadid, M. N. and Idress, M. M. (2007) "Cost estimation of structural skeleton using an interactive automation algorithm: a conceptual approach", Automat Constr, Elsevier, 16(6), 797805.

Kim, J., Lee, H., Park, M., Kim, H. and Hwang, S. (2010) A Method for Development of Rebar Quantity Take-Off(QTO) Efficiency Using BIM, Seoul. Proceedings of Korea Institute of Construction Engineering and Management Annual Conference 2010, InCheon.

Kim, M. J., Lee, K. H. and Son, C. B. (2014) "An Status Analysis on the BIM Utilization and Its Improvement Measures in Domestic Architects" Architectural Institute of Korea, 30(8), 79-86.

Kim, S. and Park, K. (2006) The Method of Reducing Loss Ratio of Reinforcement Bar., Seoul, Proceedings of Korea Institute of Construction Engineering and Management Annual Conference 2006, Yongin.

Kunwon engineering (2009). "Construction Management Guidebook" Kimoondang, Seoul, 1394.

Lee H. (2014) “An Improvement of the Quantity Take-off Process for Reducing Errors During Detailed Design Development of Building Project” Chung-Ang, Master's thesis, Seoul, 1-59.

Lee, J. J., Shin, T. H., Kim, S. A., Kang, M. K. and Chin, S. (2008) A System Development of Quantity Data Type Analysis for BIM based Automation of Estimation Framework., Seoul. Proceedings of Korea Institute of Construction Engineering and Management Annual Conference 2008, Seoul.

Lee, S. J., Lee, M. C., Seo, H. S. and Ock, J. H. (2009) A Study on the application of 3D Auto Rebar Placing Program for Effective Rebar Work., Seoul. Proceedings of Korea Institute of Construction Engineering and Management Annual Conference 2009, Daejeon.

McGraw-Hill Construction (2008) "Smart Market Report: Building Information Modeling transforming design and construction to achieve greater industry productivity" McGraw-Hill Construction. New York.

Monteiro, A. and Martins, J. P. (2013) "A survey on modeling guidelines for quantity takeofforiented BIM-based design" Automat Constr, Elsevier, 35, 238-253.

Ssangyong Engineering \& Construction Co. Ltd. (1998) "An Integrated Model for Construction Estimating Scheduling, Cost Control System." Ministry of Science and Technology of Korea, Seoul, 1-105

Yu, J., Tan, Y., and Eastman, C. (2011) Case study: Sutter health cathedral hill hospital, Collaboration in Building Information Modeling Arch 6503: BIM applications.

Zhiliang, M., Zhenhua, W., Wu, S. and Zhe, L. (2011) "Application and extension of the IFC standard in construction cost estimating for tendering in China", Automat Constr, Elsevier, 20(2), 196-204 